Document downloaded from:

http://hdl.handle.net/10251/83440

This paper must be cited as:

Li, Z.; Navarro Villalba, MT.; Martínez Triguero, LJ.; Yu, J.; Corma Canós, A. (2016).

Synthesis of nano-SSZ-13 and its application in the reaction of methanol to olefins. Catalysis Science and Technology. 6(15):5856-5863. doi:10.1039/C6CY00433D

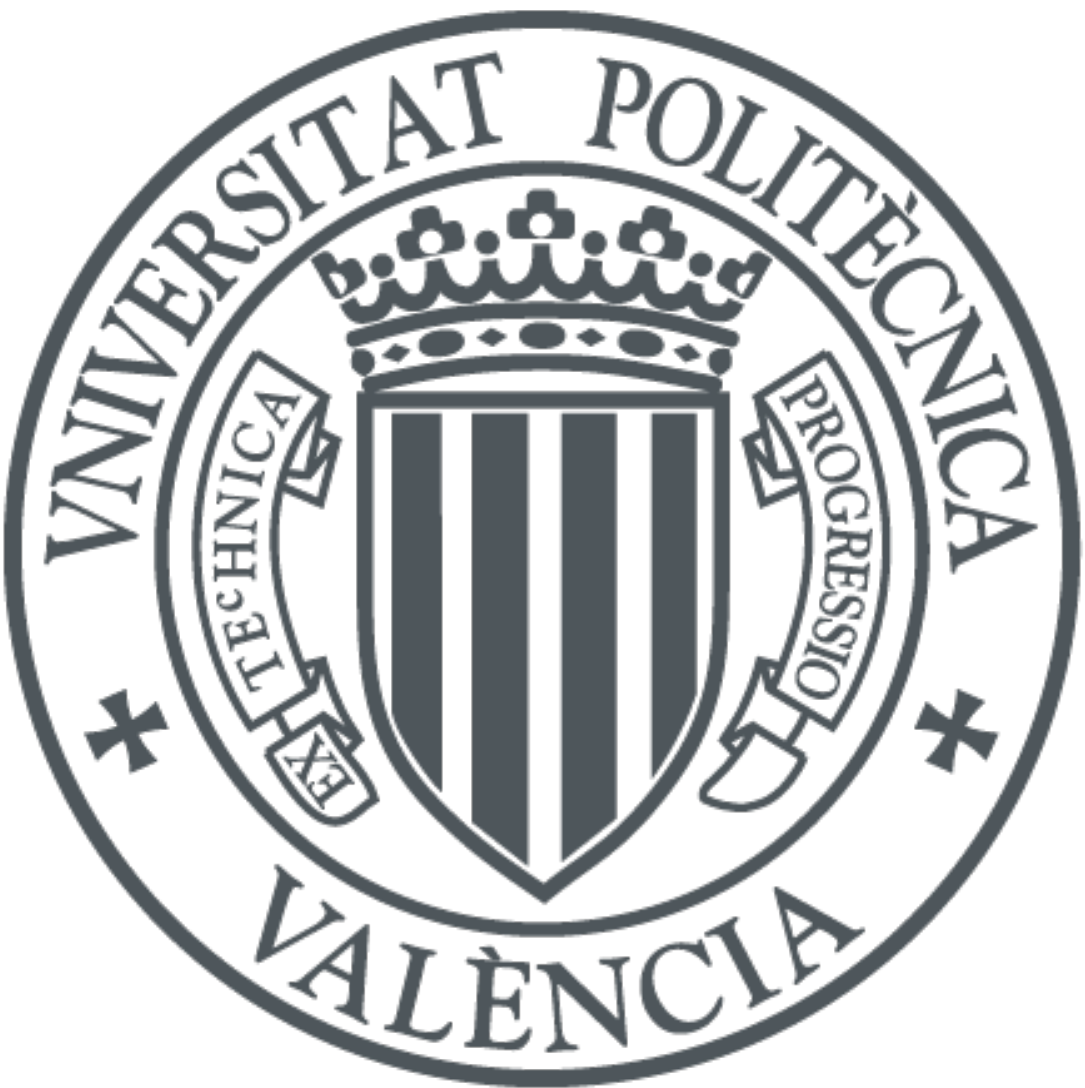

The final publication is available at

http://doi.org/10.1039/c6cy00433d

Copyright Royal Society of Chemistry

Additional Information 


\title{
Synthesis of nano-SSZ-13 and its application in the reaction of methanol to olefins
}

\author{
Z. Li ${ }^{\mathrm{a}, \mathrm{b}}$, M. T. Navarro ${ }^{\mathrm{a}}$, J. Martínez-Triguero ${ }^{\mathrm{a}}$, J. $\mathrm{Yu}^{\mathrm{c}}$, and A. Corma ${ }^{\mathrm{a}, \mathrm{d}}{ }^{*}$ \\ Nanosized SSZ-13 has been obtained from a one-pot synthesis procedure with the addition of CTAB to the synthesis \\ precursor solution. Nano-SSZ-13 zeolite showed high intracrystalline mesoporosity and comparing to standard SSZ-13 \\ presented much longer lifetime and higher conversion capacity for the reaction of methanol to olefins. The improved \\ properties were attributed to a more efficient utilization of microporosity by easier diffusion of reactants and products and \\ slower deactivation by coke. A higher $\mathrm{C} 2 / \mathrm{C} 3$ ratio was found for nano-SSZ-13 pointing to a lower deactivation of the \\ aromatics \\ cycle \\ of \\ the \\ hydrocarbon \\ pool
}

\section{Introduction}

Methanol to olefins (MTO) is an important reaction for producing ethylene and propylene which are principal chemicals for the polymer industry. This is specially so with the development of shale gas and low price of natural gas. Currently, the most widely used materials for MTO are zeolites ZSM-5(10 member-ring) and SAPO-34 (8 member-ring). ZSM-5 offers the versatility to be used to yield mainly propylene (MTP) or aromatics (MTG) depending on the reaction conditions and the framework $\mathrm{Si} / \mathrm{Al}$ ratio of the zeolite. ${ }^{1-3}$ SAPO-34 due to the size of the channels that hinder the diffusion of aromatics, it mainly yields ethylene and propylene. However, diffusion limitations for reactants and products and the formation of coke deposits in the cages of SAPO-34, results in faster deactivation and lower catalyst efficiency.

To overcome the diffusion problems, two main approaches have been proposed: a) to reduce the crystallite size of the catalyst to increase the external surface area and shorten the diffusion path length, and b)the generation of mesoporosity in the microporous zeolites. Mesopores in zeolites should favor the formation of molecules larger than the micropores, while offering mesoporous channels for fast diffusion and mass transport to avoid the coke deposition on the catalytic sites.

All that results in an improvement of the catalyst lifetime and reactant conversions. ${ }^{4}$ Following this, much effort has been devoted, especially with ZSM-5, on the direct synthesis of hierarchical zeolites, by means of: a)dual templating with hard and soft secondary SDAs, ${ }^{5-8}$ b)single multifunctional templates, ${ }^{9,}{ }^{10}$ c)varying synthesis conditions to decrease the

\footnotetext{
a. Instituto de Tecnología Química (UPV-CSIC), Universitat Politècnica de València Consejo Superior de Investigaciones Científicas, Av. de los Naranjos s/n, 46022 Valencia, Spain.

${ }^{b}$. School of Chemistry and Materials Science, Heilongjiang University, Harbin 150080, China.

State Key Laboratory of Inorganic Synthesis and Preparative Chemistry, College of Chemistry, Jilin University, Changchun, 130012, China

${ }^{d .}$ King Fahd University of Petroleum and Minerals, P. O. Box 989, Dhahran 31261,

Saudi Arabia.
}

size of the crystals ${ }^{11}{ }^{12}$ or by postsynthesis leaching treatments. ${ }^{4,13-16}$ In the case of SAPO-34, its performance has been improved by developing mesopores ${ }^{17-22}$ and by synthesizing crystals of smaller size. ${ }^{23-31}$

The use of dual templates, which implies small organic struture directing agent for the formation of micropores and large organic molecular surfactants for developing mesopores as a strategy to prepare meso-MFI, has been proposed ${ }^{32,33}$. The large molecular surfactant hexadecyl trimethyl ammonium bromide (CTAB) firstly used to prepare MCM-41 has been employed to the synthesis of hierarchical zeolites in the dual template method. However, the addition of CTAB to the synthesis gel can lead to a separation between the zeolitic phase and a mesoporous material ${ }^{33-35}$ or can yield just a mesoporous phase ${ }^{36,37}$. To prevent that, CTAB is added to a preformed solution of zeolite precursors containing primary units of zeolite seeds, nanocrystals, nanoparticles and subnanocrystals. With the addition of CTAB, the process of assembling and growth of the precursors is delayed permitting the control of the size of the crystals. ${ }^{38}$

SSZ-13 the aluminosilicate homologue of SAPO-34 with CHA topology ${ }^{39,40}$ offers an alternative for MTO. Due to its higher acidity strength, the reaction of methanol to olefins could starts at lower temperature or to allow a shorter contact time or higher throughput. ${ }^{40,41}$ However, SSZ-13 presents similar or even faster deactivation than SAPO-34. ${ }^{40}$ In order to improve the pore accessibility and diffusion to reduce the deactivation, Olsbye and co-authors modified SSZ-13 by alkaline treatment to form mesopores in the zeolite crystals. However, the success was very limited and lifetime of the material was not improved. ${ }^{42}$ In contrast, the catalytic performance of SSZ-13 was enhanced after neutron irradiation that induced structural defects. ${ }^{43}$ The use of CTAB (hexadecyl trimethyl ammonium bromide) as growth modifier in the synthesis of SSZ-13 has been recently explored by Kumar et al. ${ }^{44}$ resulting in a decrease in the size of the crystal, and, Hensen et al. have applied different co-templates for the synthesis of SSZ-13, showing increased mesoporosity and lifetime for SSZ-13. ${ }^{45,46}$ 
In this work, we have prepared nano-SSZ-13 by direct (onepot) synthesis strategy. This was done by CTAB when the zeolite precursors have already been formed, resulting in nanosized SSZ-13 crystallites. Then, the catalytic performance of that nanosized zeolite for methanol to olefins has been compared with the conventional SSZ-13. It will be shown how the reduced size of the crystallites affects selectivity, acidity, and lifetime.

\section{Experimental}

\section{Catalyst synthesis}

Conventional SSZ-13 was synthesized with the following gel composition: $0.1 \mathrm{Na}_{2} \mathrm{O}: 1 \mathrm{SiO}_{2}: 0.025 \mathrm{Al}_{2} \mathrm{O}_{3}: 0.2 \mathrm{~N}, \mathrm{~N}, \mathrm{~N}$-trimethyl-1adamantanammonium hydroxide(TMAdOH): $44 \mathrm{H}_{2} \mathrm{O}$. TMAdOH was firstly mixed with $\mathrm{NaOH}$ and deionized water at room temperature until it was dissolved completely. Then, $\mathrm{SiO}_{2}$ (Aerosil) was added to the TMAdOH solution. Finally, $\mathrm{Al}_{2} \mathrm{O}_{3}$ was dissolved into the solution mentioned above. The resulting gel was stirred at room temperature for 1 hour to obtain a homogeneous gel, which was then transferred into a Teflonlined steel autoclave and kept statically in an oven at $160^{\circ} \mathrm{C}$ for 6 days. The product was separated by filtration, washed with deionized water and dried at $100^{\circ} \mathrm{C}$. The catalyst was calcined in air at $580^{\circ} \mathrm{C}$ to remove the template. $\mathrm{H}$-SSZ-13 was obtained by ion exchange of calcined sample with $2.5 \mathrm{M} \mathrm{NH}_{4} \mathrm{Cl}$ solution $\left(80^{\circ} \mathrm{C}\right.$ and liquid to solid ratio of 10$)$ for 2 hours and then calcined at $500{ }^{\circ} \mathrm{C}$ for three hours in air.

Nano-SSZ-13 was synthesized following the same procedure and gel composition as for SSZ-13. Then, the initial gel was located in the autoclave at 160 o for 1 day and after that time $\mathrm{CTAB}$ (molar ratio $\mathrm{CTAB} / \mathrm{SiO}_{2}=0.12$ in the final gel) was mixed completely with the solution. The resultant gel, now containing $C T A B$, was transferred into the Teflon-lined autoclave again and heated at $160^{\circ} \mathrm{C}$ for 9 days. The product was recovered by filtration, washed with deionized water, dried, calcined at $580^{\circ} \mathrm{C}$, ion exchanged with $\mathrm{NH}_{4} \mathrm{Cl}$ solution and calcined at $500^{\circ} \mathrm{C}$.

\section{Characterization}

The crystallinity of the samples was followed by X-ray powder diffraction (XRD) with a Panalytical CUBIX diffractometer with monochromatic CuK $\alpha 1,2$ radiation $(\lambda=1.5406,1.5444 \AA$ 和 $\alpha 2$ / $\mathrm{K} \alpha 1$ intensity ratio $=0.5)$. The morphology and particle size of the zeolite were characterized by Scanning Electron Microscope (SEM, JEOL JSM-6300) and Transmission Electron Microscopy. The MAS NMR spectra were recorded with a Bruker AV400 spectrometer. ${ }^{29} \mathrm{Si}$ MAS NMR spectra were at $79.459 \mathrm{MHz}$ with a $60^{\circ}$ pulse length of $4 \mu \mathrm{s}$ and 60 s repetition time, spinning the sample at $5 \mathrm{kHz} .{ }^{27} \mathrm{Al}$ MAS NMR spectra were recorded at $104.218 \mathrm{MHz}$ with a spinning rate of $10 \mathrm{kHz}$ at a $90^{\circ}$ pulse length of $0.5 \mu$ s with $1 \mathrm{~s}$ repetition time. ${ }^{29} \mathrm{Si}$ and ${ }^{27} \mathrm{Al}$ chemical shifts are reported relative to tetramethylsilane and $\mathrm{Al}\left(\mathrm{H}_{2} \mathrm{O}\right)_{6}$, respectively. Elemental composition was determined by inductively coupled plasma atomic absorption spectroscopy (ICP-OES) using a Varian 715-ES. The BET surface area, micropore volume and pore volume distribution were measured by $\mathrm{N}_{2}$ adsorption and desorption in a Micromeritics ASAP2000. For low-temperature CO adsorption experiments, the samples were cooled to $77 \mathrm{~K}$ followed by $\mathrm{CO}$ dosing at increasing pressure $(0.4-8.5 \mathrm{mbar})$ and recording the IR spectrum after each dosage. After CO dosing, the samples were evacuated and the spectra collected. $\mathrm{NH}_{3}$-TPD experiments were carried out in a Micromeritics 2900 apparatus. A calcined sample (100 $\mathrm{mg}$ ) was activated by heating to $400^{\circ} \mathrm{C}$ for $2 \mathrm{~h}$ in an oxygen flow and for $2 \mathrm{~h}$ in argon flow. Subsequently, the samples were cooled down at $176^{\circ} \mathrm{C}$, and $\mathrm{NH}_{3}$ was adsorbed. The $\mathrm{NH}_{3}$ desorption was monitored with a quadrupole mass spectrometer (Balzers, Thermo Star GSD 300T) while the temperature of the sample was ramped at $10^{\circ} \mathrm{C} \mathrm{m^{-1 }}$ in helium flow. Total ammonia adsorption was measured by repeated injection of calibrated amounts of ammonia at $176^{\circ} \mathrm{C}$ until saturation. Ammonia desorption was recorded by means of the mass 15 , since this mass is less affected by the water desorbed.

\section{Catalytic experiments}

The catalyst was pelletized, crushed and sieved into 0.2-0.4 $\mathrm{mm}$ particle size. $50 \mathrm{mg}$ of sample were mixed with $2 \mathrm{~g}$ quartz (Fluka) before being introduced into the fix-bed reactor $(7 \mathrm{~mm}$ diameter). $\mathrm{N}_{2}(30 \mathrm{~mL} / \mathrm{min})$ was bubbled in methanol hold at $17^{\circ} \mathrm{C}$, giving a WHSV $=0.8 \mathrm{~h}^{-1}$. The catalyst was first activated with a nitrogen flow of $80 \mathrm{~mL} / \mathrm{min}$ for $1 \mathrm{~h}$ at $540^{\circ} \mathrm{C}$, and then the temperature was decreased to reaction conditions $\left(350^{\circ} \mathrm{C}\right)$. Each experiment was analyzed every 5 minutes with two online gas chromatographs (BRUKER 450GC, with PONA and $\mathrm{Al}_{2} \mathrm{O}_{3}$-Plot capillary columns, and FID detectors). After reaction, the catalyst was regenerated at $540^{\circ} \mathrm{C}$ in $80 \mathrm{ml}$ of air for $3 \mathrm{~h}$ and the reaction was repeated again. Conversion and selectivities were considered in carbon basis and methanol and dimethylether were lumped together for calculation of conversion.

\section{Results and discussion}

\section{Characterization}

The XRD patterns of the synthesized standard SSZ-13 and nano-SSZ-13 after template removal by calcination are shown in Fig.1. The nano-SSZ-13 sample shows same peaks position and shapes as the standard SSZ-13, which correspond to the CHA topology type structure. However, the intensity of the peaks in the nano-SSZ-13 is lower, which could be assigned to partial loss of micropore volume and/or to a decrease in the size of the crystal. Fig.2 shows the SEM and TEM images of the standard and the nano-SSZ-13. The standard SSZ-13 presents highly overlapped growth and irregular crystals with size in the range of $1.5-2.5 \mu \mathrm{m}$, while the nano-SSZ-13 shows different morphology with aggregates of nanoscale size in the range of 50-200 nm. The TEM images confirm that with the addition of surfactant the size of the crystallites of nano-SSZ-13 is much smaller than standard SSZ-13 and presents interparticle mesoporosity. 


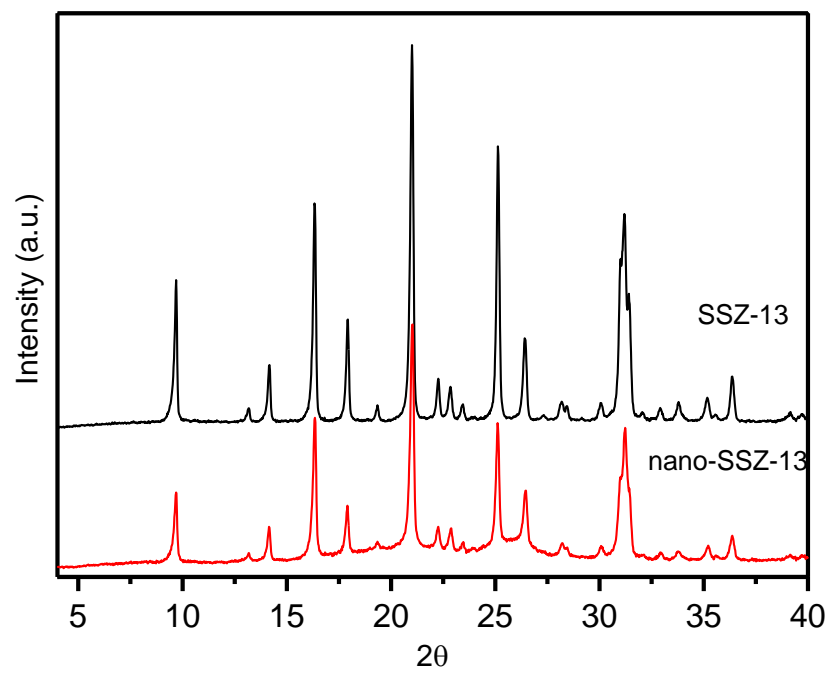

Figure 1. The XRD patterns of the synthesized standard SSZ-13 and nano-SSZ-13.

Further information can be obtained from the $\mathrm{N}_{2}$ adsorption isotherms showed in Fig.S1, and the textural properties of the samples are summarized in Table 1. Fig.S1 shows that SSZ-13 synthesized in the traditional way exhibits a type I isotherm due to the microporosity. On the other hand, nano-SSZ-13 presents characteristic isotherm of type IV with the initial stage of steep uptake due to the micropore and another sharp inflection at $\mathrm{P} / \mathrm{P}^{0}=0.8-1.0$ which is assigned to condensation in the interparticles. The final uptake at high pressure agrees with an interparticle mesoporosity due to the small nanocrystals of nano-SSZ-13. Pore size distribution (PSD) of nano-SSZ-13 (Fig. S1) presents a narrow peak at $3 \mathrm{~nm}$ typical of mesoporous materials ${ }^{4}$. The isotherm is very similar to that obtained with nano-SAPO-34 with crystal size of $20 \mathrm{~nm}$ as presented in our previous work ${ }^{30}$.

Both samples show similar BET surface areas, though the nano-SSZ-13 sample presents much higher external surface area $\left(129 \mathrm{~m}^{2} / \mathrm{g}\right)$, much larger mesopore and lower micropore volume than the standard SSZ-13 (see Table 1). The high external surface of nano-SSZ-13 should offer increased accessibility, with the corresponding impact on the catalytic performance in the reaction of methanol to olefins.

Acidity of samples measured by adsorption of ammonia is shown in Fig.S2. When comparing the shape of the $\mathrm{NH}_{3}$ desorption curves (Fig.S2), the two samples present a main desorption band with a maximum in the range from 337 to $407^{\circ} \mathrm{C}$ corresponding to Brönsted acidity. The lower intensity of the nano-SSZ-13 corresponds to a lower amount of acid
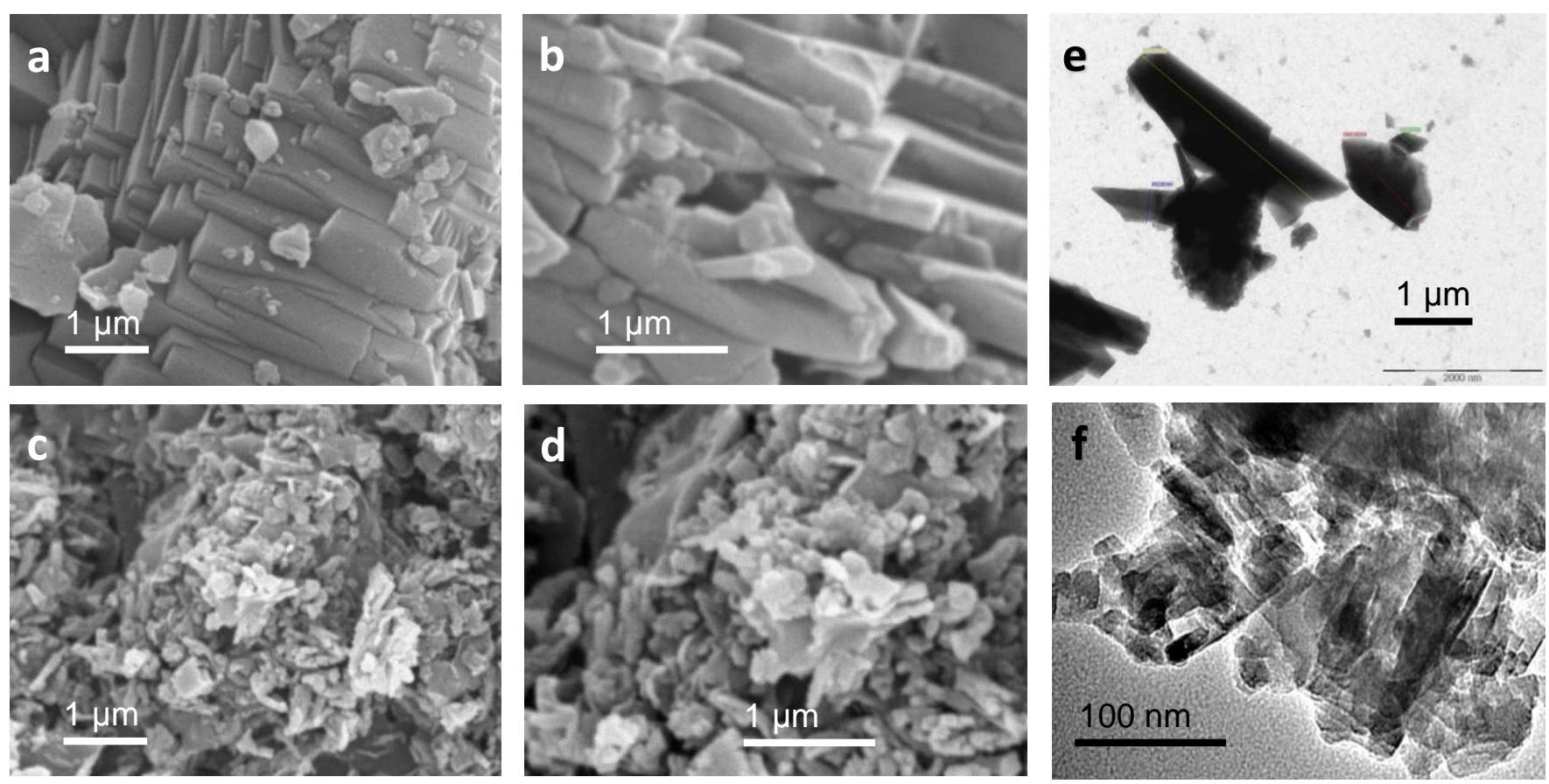

Figure 2. SEM images of the standard SSZ-13, a, b); nano SSZ-13, c, d) and TEM images of Standard SSZ-13, e); nano SSZ-13, f).

Table 1. Textural properties of the standard-SSZ-13 and nano-SSZ-13.

\begin{tabular}{|c|c|c|c|c|c|c|c|c|c|}
\hline SAMPLE & $\mathrm{Si} / \mathrm{Al}$ & SDA & $\mathrm{T}\left({ }^{\circ} \mathrm{C}\right)$ & $\begin{array}{c}t \\
\text { (d) }\end{array}$ & $\begin{array}{c}\text { BET } \\
\left(\mathrm{m}^{2} / \mathrm{g}\right)\end{array}$ & $\begin{array}{c}A_{\text {micro }} \\
\left(\mathrm{m}^{2} / \mathrm{g}\right)\end{array}$ & $\begin{array}{c}A_{\text {Ext }} \\
\left(\mathrm{m}^{2} / \mathrm{g}\right)\end{array}$ & $\begin{array}{c}V_{\text {micro }} \\
\left(\mathrm{cm}^{3} / \mathrm{g}\right)\end{array}$ & $\begin{array}{c}V_{\text {meso }} \\
\left(\mathrm{cm}^{3} / \mathrm{g}\right)\end{array}$ \\
\hline SSZ-13 & 15.3 & TMAdOH & 160 & 6 & 520 & 517 & 3 & 0.253 & 0.093 \\
\hline nano-SSZ-13 & 17 & TMAdOH+CTABr & 160 & $1+9$ & 530 & 401 & 129 & 0.204 & 0.446 \\
\hline
\end{tabular}


Table 2. Framework Si/Al ratio from ${ }^{29} \mathrm{Si}$ NMR deconvolution and acidity measured by adsorption of $\mathrm{NH}_{3}$ at $175^{\circ} \mathrm{C}$ of calcined samples.

\begin{tabular}{cccc}
\hline Sample & $\begin{array}{c}\text { Si/Al } \\
\text { (framework) }\end{array}$ & $\begin{array}{c}\text { Si-OH defects } \\
\text { (wt\%) }\end{array}$ & $\begin{array}{c}\mathbf{N H}_{3} \\
\text { (mmol/g) }\end{array}$ \\
\hline SSZ-13 & 16.5 & 5.6 & 0.66 \\
Nano-SSZ-13 & 25.6 & 8.2 & 0.43 \\
\hline
\end{tabular}

sites compared with standard SSZ-13, which agrees with its lower aluminum content. The shoulder at $650^{\circ} \mathrm{C}$ corresponds to interference with water due to dehydroxylation at high

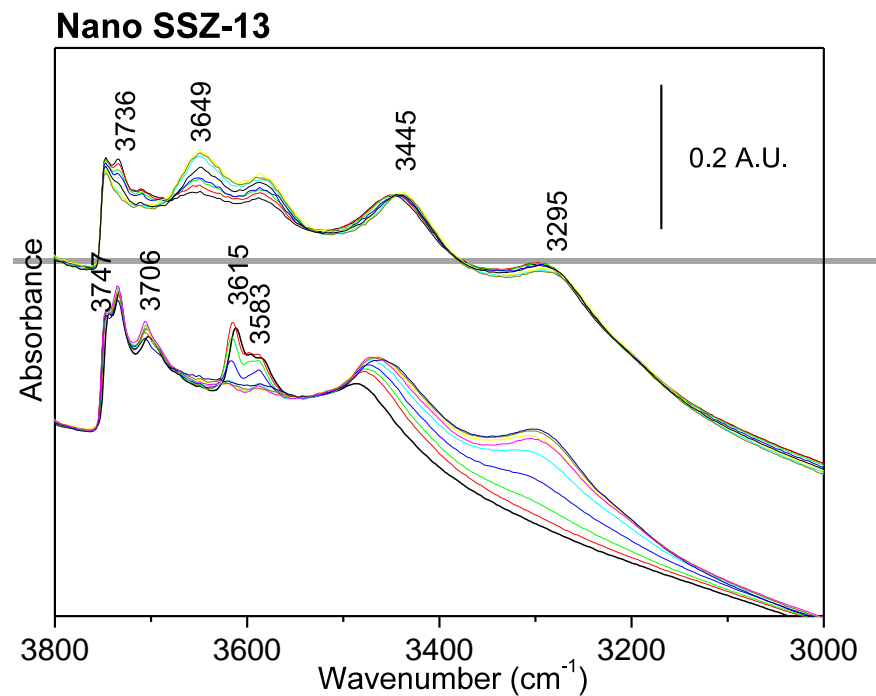

Standard SSZ-13

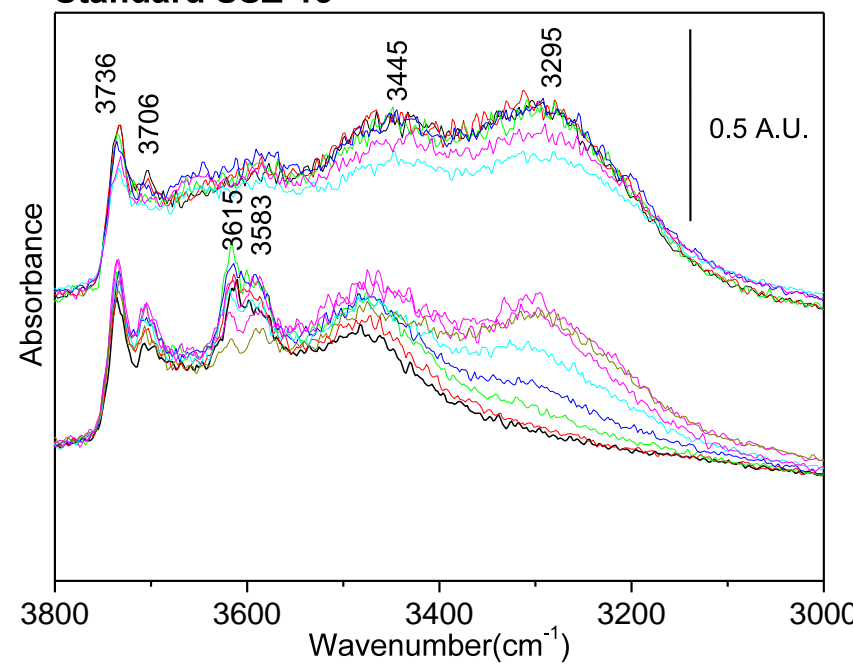

temperature.

The ${ }^{27}$ AI NMR MAS spectra of all samples are shown in Fig.S3. All spectra present a dominant signal at $57 \mathrm{ppm}$ characteristic of tetracoordinated framework aluminum and a low intensity peak at around $-2 \mathrm{ppm}$ due to the presence of octahedral extra-framework aluminum. The signal at 57 of nano-ssz-13 is more asymmetrical and also presents a small broad band of octahedral aluminum close to $0 \mathrm{ppm}$ that is sharper for standard SSZ-13.

Information about the structural defects and different $\mathrm{Si}$ coordination is given in the ${ }^{29} \mathrm{Si} N \mathrm{NMR}$ spectra (Fig.S4). The samples show resonances at $-112,-106$ corresponding to $\mathrm{Si}(4 \mathrm{Si}), \mathrm{Si}(3 \mathrm{Si} 1 \mathrm{Al})$, and other signal at -102 that has been assigned to $\mathrm{Si}-\mathrm{OH}$ (defects) ${ }^{47}$. The presence of mesoporosity in nano-SSZ-13 is reflected in a decrease in the -106 signal while the signal at $-102 \mathrm{ppm}$ due to structural defects increases comparing to the standard SSZ-13(see in Table 2). The adsorption of $\mathrm{CO}$ at low temperature has been carried out to

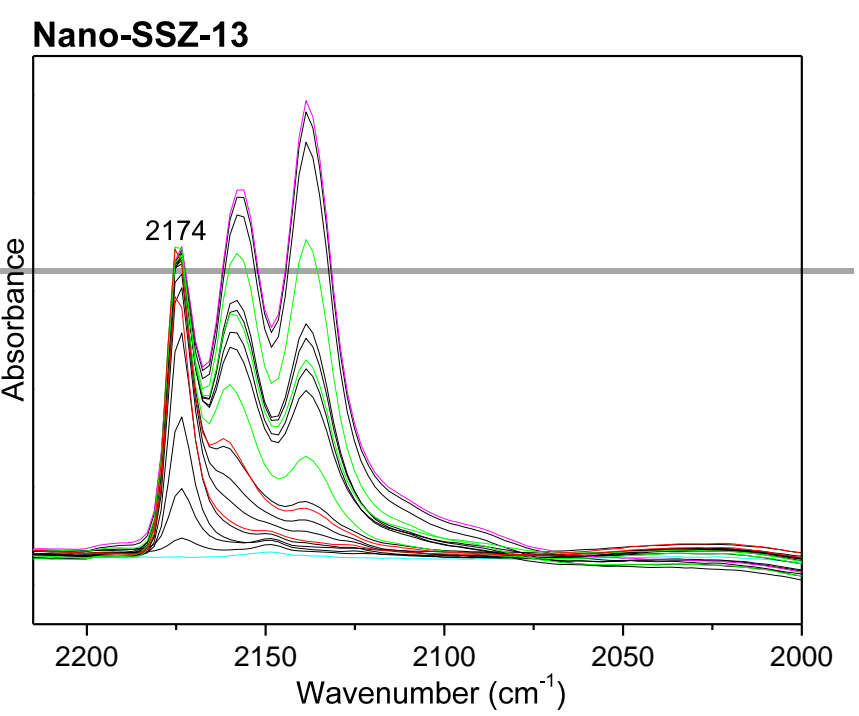

Standard SSZ-13

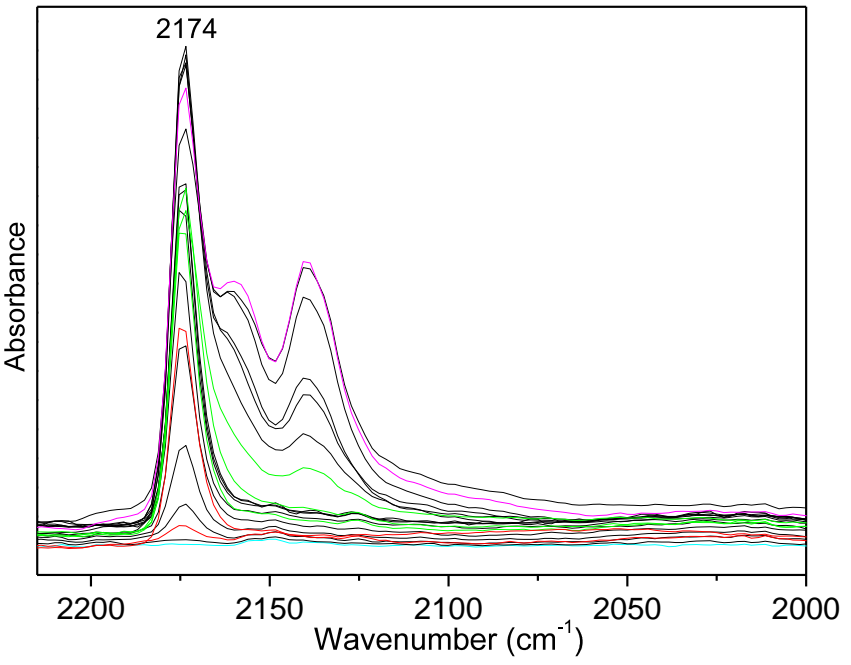

characterize the acidity of standard and nano-SSZ-13, and the results are presented in Fig.3. For both samples the bands assigned to HF and LF Brönsted acid sites ${ }^{41}$ (3615 and $3583 \mathrm{~cm}$ $\left.{ }^{1}\right)$ decrease after adsorption due to the interaction of $\mathrm{CO}$ with bridging hydroxyl groups, that produces a shift in the bands to a single signal at $3295 \mathrm{~cm}^{-1}$. At higher CO pressures, the external silanols also interact with $\mathrm{CO}$ and shift from 3747- 
$3706 \mathrm{~cm}^{-1}$ to a doublet at 3649 and $3587 \mathrm{~cm}^{-1}$. The band associated to silanol nests band (or internal defects) at 3480 $\mathrm{cm}^{-1}$ shifts to $3445 \mathrm{~cm}^{-1}$. The band associated to the interaction of CO with silanols in nano-SSZ-13 is larger than for standardSSZ-13 in agreement with its higher amount of defects as determined by ${ }^{29} \mathrm{Si}$ NMR (see Table 2). After CO adsorption, the signal in the CO stretching region appearing at $2174 \mathrm{~cm}^{-1}$ (Fig. 3 right), is a characteristic band assigned to $\mathrm{CO}$ interacting with Brönsted sites. At higher pressures of $\mathrm{CO}$, signals of interaction with silanols groups appear at lower frequencies. The shift of the bands corresponding to Brönsted acidity in the $\mathrm{OH}$ region and the position of the characteristic band in the $\mathrm{CO}$ region is the same for standard and nano-SSZ-13. Therefore, from $\mathrm{CO}$ adsorption we cannot see any differences in acid strength between the two samples.

\section{Catalytic performance}

The activity of the samples for the reaction of methanol to olefins at WHSV $=0.8 \mathrm{~h}^{-1}$ and $350{ }^{\circ} \mathrm{C}$ is shown in Fig.4. These reaction conditions have been used recently by $\mathrm{Wu}$ et al. ${ }^{43,46}$

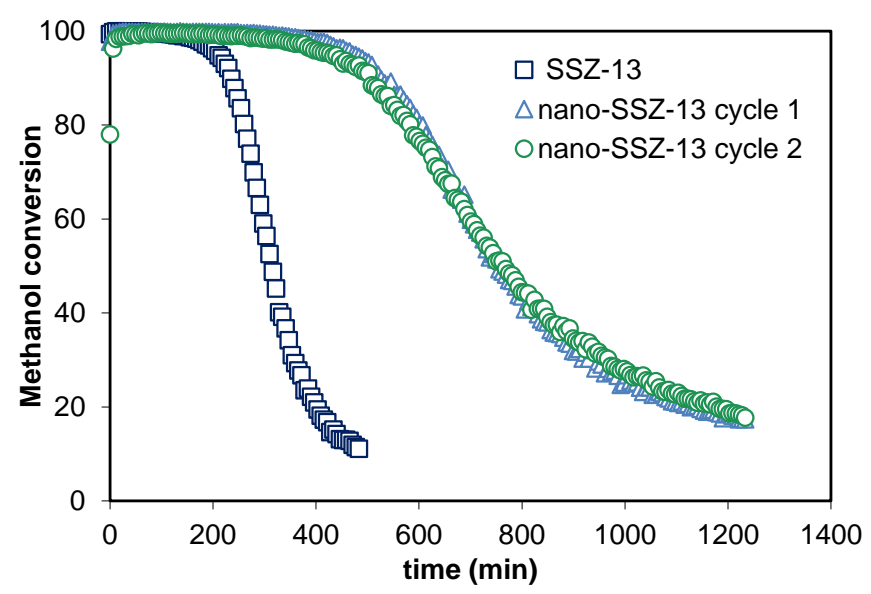

Figure 4. Conversion of methanol at $350^{\circ} \mathrm{C}$ and WHSV $=0.8 \mathrm{~h}^{-1}$ on standard and nano-SSZ-13.

\begin{tabular}{cccccc}
\hline \multicolumn{2}{l}{$\begin{array}{l}\text { Table 3. K, a, half lifetime, breakthrough time and conversion capacity } \\
\text { values of SSZ-13 and nano-SSZ-13 }\end{array}$ from the fitting of the Janssens' model. ${ }^{47}$} \\
\hline Sample & $\begin{array}{c}\mathrm{K} \\
(\mathrm{mol} / \mathrm{gcat} \mathrm{h})\end{array}$ & $\begin{array}{c}\mathrm{a} \\
(\mathrm{g} / \mathrm{mol})\end{array}$ & $\begin{array}{c}\mathrm{t}_{0.5} \\
(\mathrm{~min})\end{array}$ & $\begin{array}{c}\mathrm{t}_{0.98} \\
(\mathrm{~min})\end{array}$ & $\begin{array}{c}\mathrm{R} \\
\left(\mathrm{g}_{\text {meoh }} / \mathrm{g}_{\text {cat }}\right)\end{array}$ \\
\hline SSZ-13 & 10.05 & 0.00260 & 314 & 165.8 & 4.2 \\
nano-SSZ-13 & 6.52 & 0.00104 & 783 & 212.3 & 10.4 \\
\hline
\end{tabular}

for testing mesoporous SSZ-13 samples obtained by adding mesoporogen agents to the synthesis gel and hence, the results obtained with nano-SSZ-13 can be compared with those mesoporous SSZ-13 samples previously reported. As it can be seen, all samples show initial $100 \%$ conversion. After a certain period, the conversion decreases with time on stream due to catalyst deactivation. It is important to note that nanoSSZ-13 obtained here shows much longer lifetime than the standard SSZ-13. This would be in agreement with the presence of intercrystalline mesoporosity and lower path length in the crystals, which improves the diffusion rate and decreases the negative effect of coke in the channels. Indeed, in the case of standard SSZ-13 conversion decreases to $50 \%$ after $310 \mathrm{~min}$, while for nano-SSZ-13 50\% conversion is obtained at $760 \mathrm{~min}$.

\section{Standard-SSZ-13}

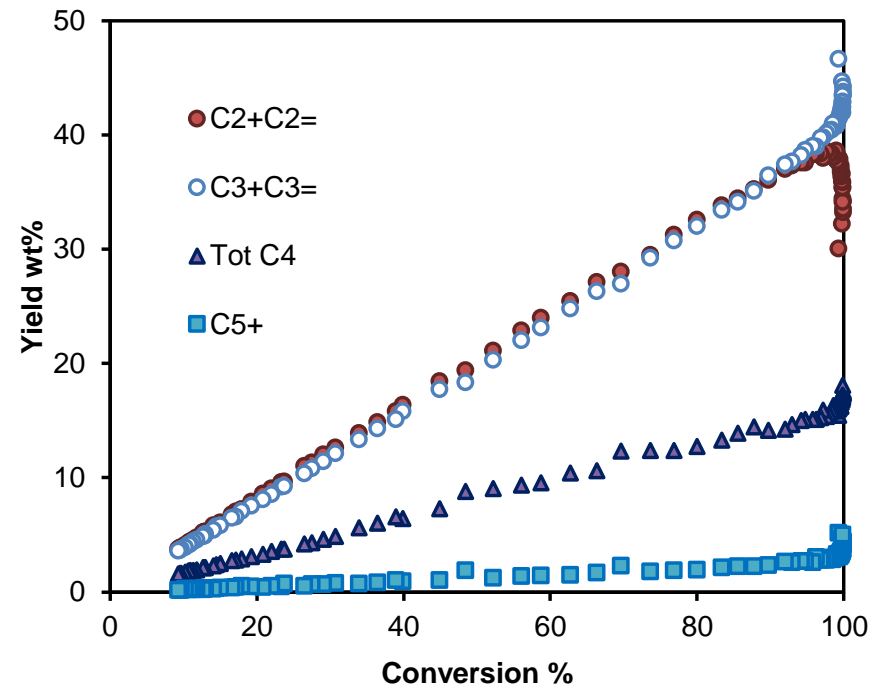

Nano-SSZ-13

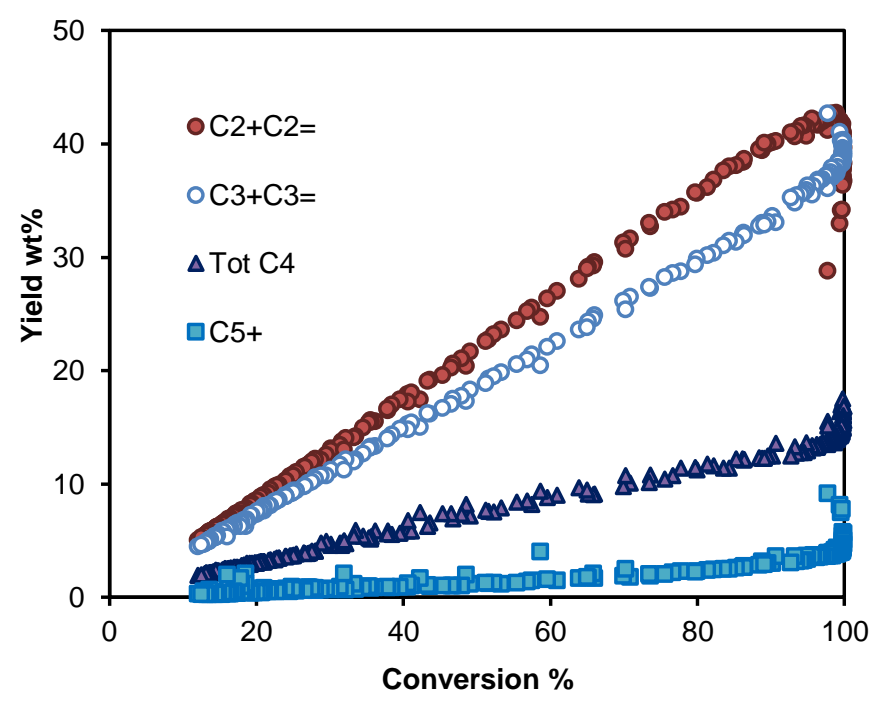

Figure 5. Yields to $\mathrm{C} 2, \mathrm{C} 3, \mathrm{C} 4$ and $\mathrm{C} 5$ + hydrocarbons in the conversion of standard and nano-SSZ- 13 at $350^{\circ} \mathrm{C}$ and $\mathrm{WHSV}=0.8 \mathrm{~h}^{-1}$. 


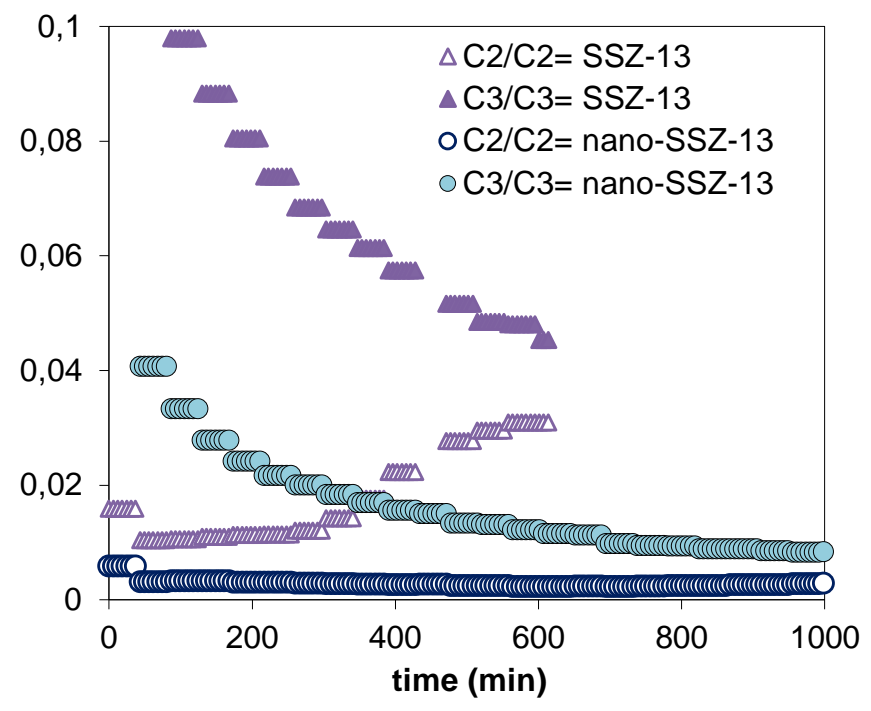

Figure 6. The hydrogen transfer index of the samples in the conversion of methanol.

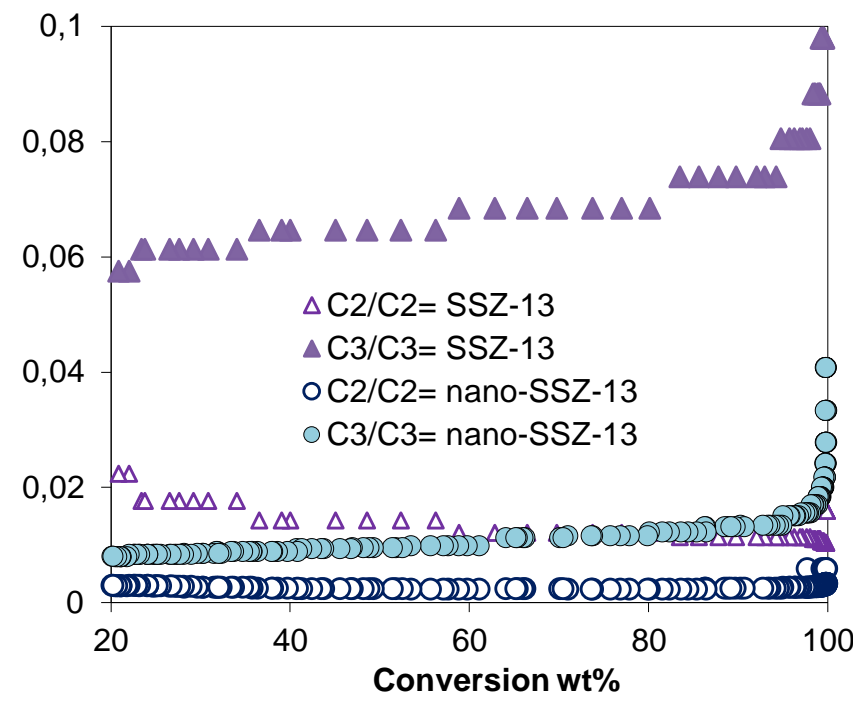

When comparing selectivities at constant conversion (Fig. S5) it can be seen that the $\mathrm{C} 2 / \mathrm{C} 3$ ratio increases in the nano-SSZ-13 with respect to standard SSZ-13. More specifically, the results have shown an effective increase in the selectivity to ethylene, while the distribution among the other olefins is not affected. The different behavior of $\mathrm{C} 2$ for nano and standard SSZ-13, while $\mathrm{C} 3, \mathrm{C} 4$ and $\mathrm{C} 5$ are very similar, points out the existence of a dual reaction cycle i.e. the aromatic and the olefin cycles (see scheme S1) to explain the yield of products obtained. The two cycles have also been proposed for reaction of methanol with $\mathrm{ZSM}-5^{51}$. The two mechanisms, the olefin and the aromatics cycle yield different distribution of products. The aromatic cycle mainly produces ethylene while the olefin cycle yields $\mathrm{C} 3$ to $\mathrm{C} 5$ olefins by methylation-cracking of an adsorbed olefin. In the case of 8R zeolites as SAPO-34, SSZ-13 and others it appears that the aromatic cycle is predominant, ${ }^{52}$ without discarding completely the contribution of the olefin cycle ${ }^{53,54}$. If that is so, the higher selectivity to ethylene of nano-SSZ-13 should be related to a higher contribution of the aromatics cycle into the final product distribution.

The values for the hydrogen transfer index $\left(\mathrm{HTI}, \mathrm{C} 3 / \mathrm{C}^{3}\right.$ $\left.\mathrm{C} 2 / \mathrm{C2}^{=}\right)$are given in Fig.6. The result clearly shows that standard-SSZ-13 presents higher amount of hydrogen transfer reactions compared to nano-SSZ-13. Since hydrogen transfer is closely related to the formation of coke, it follows that the standard-SSZ-13 should deactivate faster, which is in agreement with the results obtained in the reaction of methanol. Moreover, the higher hydrogen transfer and the faster deactivation of standard-SSZ-13 could also explain a lower contribution of the aromatic cycle in the dual cycle concept of the reaction. In this way, the aromatics that are part of the hydrocarbon pool in standard-SSZ-13 are more prone to grow and develop coke by successive methylation, cyclization and hydrogen transfer, becoming deactivated. On controlled by diffusion during deactivation. 
the contrary, in the case of nano-SSZ-13, the aromatic cycle, once formed, because of the slower deactivation, contributes more to the formation of products than in the case of SSZ-13.

\section{Conclusions}

We have demonstrated that a nanosized SSZ-13 zeolite can be obtained from one-pot synthesis procedure by addition of surfactant to conventional synthesis precursor. The material exhibits much longer lifetime than the standard SSZ-13. This is mainly due to the presence of smaller crystallites and intercrystalline mesoporosity, which facilitates a more efficient use of the catalyst. A higher $\mathrm{C} 2 / \mathrm{C} 3$ ratio was found in the nano-SSZ-13, which can be explained due to a lower contribution of hydrogen transfer reactions leading to lower deactivation of the aromatics-based hydrocarbon pool.

\section{Acknowledgements}

Financial support by the Spanish Government-MINECO through "Severo Ochoa" (SEV 2012-0267), CTQ2015-67592-P, CTQ2015-70126-R, CTQ2015-68951-C3-1-R, MAT2015-71842$P$, by the European Union ERC-AdG-2014-671093SynCatMatch and by the Generalitat Valenciana PROMETEOII/2013/011 is acknowledged Z. Li acknowledges China Scholarship Council (CSC) for a fellowship. J. Yu thanks the Major International Joint Research Project of China for financial supports (Grant No. 21320102001).

\section{References}

1 C. D. Chang, C. T. W. Chu and R. F. Socha, J. Catal., 1984, 86 289-296.

2 U. Olsbye, S. Svelle, M. Bjorgen, P. Beato, T. V. Janssens, F. Joensen, S. Bordiga and K. P. Lillerud, Angew. Chem. Int. Ed., 2012, 51, 5810-5831.

3 M. Stöcker, in Zeolites and Catalysis, Wiley-VCH Verlag GmbH \& Co. KGaA, 2010, pp. 687-711.

4 K. Möller and T. Bein, Chem. Soc. Rev., 2013, 42, 3689-3707.

5 C. J. H. Jacobsen, C. Madsen, J. Houzvicka, I. Schmidt and A. Carlsson, J. Am. Chem. Soc., 2000, 122, 7116-7117.

6 V. N. Shetti, J. Kim, R. Srivastava, M. Choi and R. Ryoo, J. Catal., 2008, 254, 296-303.

7 D. P. Serrano, R. A. García, G. Vicente, M. Linares, D. Procházková and J. Čejka, J. Catal., 2011, 279, 366-380.

8 M. Choi, H. S. Cho, R. Srivastava, C. Venkatesan, D.-H. Choi and R. Ryoo, Nat. Mater., 2006, 5, 718-723.

9 M. Choi, K. Na, J. Kim, Y. Sakamoto, O. Terasaki and R. Ryoo, Nature, 2009, 461, 246-249.

10 K. Na, C. Jo, J. Kim, K. Cho, J. Jung, Y. Seo, R. J. Messinger, B. F. Chmelka and R. Ryoo, Science, 2011, 333, 328-332.

11 M. Firoozi, M. Baghalha and M. Asadi, Catal. Commun., 2009, 10, $1582-1585$.

12 Z. Qin, L. Lakiss, L. Tosheva, J.-P. Gilson, A. Vicente, C. Fernandez and V. Valtchev, Adv. Funct. Mater., 2014, 24, 257-264.

13 J. C. Groen, L. A. A. Peffer, J. A. Moulijn and J. Pérez-Ramírez, Colloids and Surfaces A: Physicochemical and Engineering Aspects, 2004, 241, 53-58.
14 J. C. Groen, W. Zhu, S. Brouwer, S. J. Huynink, F. Kapteijn, J. A. Moulijn and J. Pérez-Ramírez, J. Am. Chem. Soc., 2006, 129, 355-360.

15 B. Gil, Ł. Mokrzycki, B. Sulikowski, Z. Olejniczak and S. Walas, Catal. Today, 2010, 152, 24-32.

16 M. Bjørgen, F. Joensen, M. Spangsberg Holm, U. Olsbye, K.-P. Lillerud and S. Svelle, Appl. Catal., A, 2008, 345, 43-50.

17 S.-T. Yang, J.-Y. Kim, H.-J. Chae, M. Kim, S.-Y. Jeong and W.-S. Ahn, Mater. Res. Bull., 2012, 47, 3888-3892.

18 Y. Cui, Q. Zhang, J. He, Y. Wang and F. Wei, Particuology, 2013, 11, 468-474.

19 H. Yang, Z. Liu, H. Gao and Z. Xie, J. Mater. Chem., 2010, 20, 3227-3231.

20 J. Zhu, Y. Cui, Y. Wang and F. Wei, Chem. Commun., 2009, 3282-3284.

21 F. Schmidt, S. Paasch, E. Brunner and S. Kaskel, Microporous Mesoporous Mater., 2012, 164, 214-221.

22 X. Chen, A. Vicente, Z. Qin, V. Ruaux, J.-P. Gilson and V. P. Valtchev, Chem. Commun., 2016, 52, 3512-3515.

23 S. Lin, J. Li, R. Sharma, J. Yu and R. Xu, Top. Catal., 2010, 53, 1304-1310.

24 Y. Hirota, K. Murata, S. Tanaka, N. Nishiyama, Y. Egashira and K. Ueyama, Mater. Chem. Phys., 2010, 123, 507-509.

25 T. Álvaro-Muñoz, C. Márquez-Álvarez and E. Sastre, Catal. Today, 2013, 213, 219-225.

26 T. Álvaro-Muñoz, C. Márquez-Álvarez and E. Sastre, Catal. Today, 2012, 179, 27-34.

27 P. Wang, D. Yang, J. Hu, J. a. Xu and G. Lu, Catal. Today, 2013, 212, 62.e61-62.e68.

28 M. Yang, P. Tian, C. Wang, Y. Yuan, Y. Yang, S. Xu, Y. He and Z. Liu, Chemical commun., 2014, 50, 1845-1847.

29 G. Yang, Y. Wei, S. Xu, J. Chen, J. Li, Z. Liu, J. Yu and R. Xu, J. Phys. Chem. C, 2013, 117, 8214-8222.

30 Z. Li, J. Martinez-Triguero, P. Concepcion, J. Yu and A. Corma, PCCP, 2013, 15, 14670-14680.

31 C. Wang, M. Yang, P. Tian, S. Xu, Y. Yang, D. Wang, Y. Yuan and Z. Liu, J. Mater. Chem A, 2015, 3, 5608-5616.

32 L. Emdadi, Y. Wu, G. Zhu, C.-C. Chang, W. Fan, T. Pham, R. F. Lobo and D. Liu, Chem. Mater., 2014, 26, 1345-1355.

33 A. Karlsson, M. Stöcker and R. Schmidt, Microporous Mesoporous Mater., 1999, 27, 181-192.

34 Q. Wang, S. Xu, J. Chen, Y. Wei, J. Li, D. Fan, Z. Yu, Y. Qi, Y. He, S. Xu, C. Yuan, Y. Zhou, J. Wang, M. Zhang, B. Su and Z. Liu, RSC Advances, 2014, 4, 21479-21491.

35 M. L. Gonçalves, L. D. Dimitrov, M. H. Jordão, M. Wallau and E. A. Urquieta-González, Catal. Today, 2008, 133-135, 69-79.

36 Y. Liu, W. Zhang and T. J. Pinnavaia, Angew. Chem. Int. Ed., 2001, 40, 1255-1258.

37 K. S. Triantafyllidis, E. F. lliopoulou, E. V. Antonakou, A. A. Lappas, H. Wang and T. J. Pinnavaia, Microporous Mesoporous Mater., 2007, 99, 132-139.

38 Y. Zhu, Z. Hua, J. Zhou, L. Wang, J. Zhao, Y. Gong, W. Wu, M. Ruan and J. Shi, Chem. Eur. J., 2011, 17, 14618-14627.

39 L.-T. Yuen, S. I. Zones, T. V. Harris, E. J. Gallegos and A. Auroux, Microporous Mater., 1994, 2, 105-117.

40 F. Bleken, M. Bjørgen, L. Palumbo, S. Bordiga, S. Svelle, K.-P. Lillerud and U. Olsbye, Top. Catal., 2009, 52, 218-228.

41 S. Bordiga, L. Regli, D. Cocina, C. Lamberti, M. Bjorgen and K. P. Lillerud, J. Phys. Chem. B, 2005, 109, 2779-2784.

42 L. Sommer, D. Mores, S. Svelle, M. Stöcker, B. M. Weckhuysen and U. Olsbye, Microporous Mesoporous Mater., 2010, 132, 384-394.

43 L. Sommer, A. Krivokapić, S. Svelle, K. P. Lillerud, M. Stöcker and U. Olsbye, J. Phys. Chem. B, 2011, 115, 6521-6530.

44 M. Kumar, H. Luo, Y. Roman-Leshkov and J. D. Rimer, J. Am. Chem. Soc., 2015, 137, 13007-13017.

45 L. Wu, V. Degirmenci, P. C. M. M. Magusin, B. M. Szyja and E. J. M. Hensen, Chem. Commun., 2012, 48, 9492-9494. 
46 L. Wu, V. Degirmenci, P. C. M. M. Magusin, N. J. H. G. M. Lousberg and E. J. M. Hensen, J. Catal., 2013, 298, 27-40.

47 J. Barras, J. Klinowski and D. W. McComb, J. Chem. Soc., Faraday Trans., 1994, 90, 3719-3723.

48 T. V. W. Janssens, J. Catal., 2009, 264, 130-137.

49 Z. Li, J. Martínez-Triguero, J. Yu and A. Corma, J. Catal., 2015, 329, 379-388.

50 T. Álvaro-Muñoz, C. Márquez-Álvarez and E. Sastre, Top. Catal., 2015, 1-14

51 M. Bjørgen, S. Svelle, F. Joensen, J. Nerlov, S. Kolboe, F. Bonino, L. Palumbo, S. Bordiga and U. Olsbye, J. Catal., 2007, 249, 195-207.

52 J. Chen, J. Li, C. Yuan, S. Xu, Y. Wei, Q. Wang, Y. Zhou, J. Wang, M. Zhang, Y. He, S. Xu and Z. Liu, Cat. Sci. Technol., 2014, 4, 3268-3277.

53 W. Dai, C. Wang, M. Dyballa, G. Wu, N. Guan, L. Li, Z. Xie and M. Hunger, ACS Catal., 2015, 5, 317-326.

54 C.-M. Wang, Y.-D. Wang, Y.-J. Du, G. Yang and Z.-K. Xie, Cat. Sci. Technol., 2015, 5, 4354-4364. 